\title{
A Review on Impacts of COVID 19 Pandemic on Day-to-Day Life
}

\author{
Abduelmula Abduelkarem ${ }^{1}$, Suleiman Sharif ${ }^{1}$, and Rubian Sharif ${ }^{2}$ \\ ${ }^{1}$ University of Sharjah College of Pharmacy \\ ${ }^{2}$ University of Benghazi
}

November 9, 2020

\begin{abstract}
The number of active cases of COVID 19 and deaths is markedly escalating. The pandemic had affected almost every aspect of our lives including geopolitics, health, economics, education and sociocultural events. However, the pandemic crisis besides its negative impacts succeeded in initiating some positive impacts as well. These are represented by increasing our awareness of the importance of daily hygienic practices, digital inequality, benefits of global collaboration in research and the search for a promising vaccine, online education, close family relationships and much more. This review addresses the impacts of COVID 19 pandemic on various important aspects of life.
\end{abstract}

\section{Hosted file}

Impacts of COVID 19 Pandemic.docx-IJCP-2020.pdf available at https://authorea.com/users/ 374111/articles/491728-a-review-on-impacts-of-covid-19-pandemic-on-day-to-day-life 